\title{
PINTURAS DE GONCCALO FRANCISCO XAVIER: ANÁLISE ESTILÍSTICA E ICONOGRÁFICA
}

\author{
Jáder Barroso Neto
}

Breno Marques Ribeiro de Faria

Flávia Klausing Gervásio

Sabrina Mara Sant'Anna

Universidade Federal de Minas Gerais - Grupo de pesquisa: Cultura Artística e Metodologia na pesquisa em Artes Visuais

O objetivo de nosso artigo é identificar a "caligrafia" do pintor Gonçalo Francisco Xavier, cuja presença é documentalmente atestada em Minas Gerais entre os anos 1742 e 1772 . Analisaremos o trabalho deste artista nos forros dos seguintes templos:

- Capela de Santanna, localizada em Cocais (distrito de Barão de Cocais): os forros da capela-mor, da sacristia e dois (02) painéis parietais da capela-mor.

- Capela de Santa Quitéria, erigida em Catas Altas do Mato Dentro: o forro da capela-mor.

- Igreja de Nossa Senhora do Rosário, construída em Catas Altas do Mato Dentro: o forro da capelamor.

- Matriz de Santo Antônio, localizada em Santa Bárbara: o entablamento da portada da Capela do Santíssimo Sacramento e a pintura original de quatro (04) tábuas lá encontradas durante trabalhos de restauração constituintes de um forro(apresentam perda da policromia original em faixas no eixo longitudinal).

- Igreja de Nossa Senhora do Perpétuo Socorro, erigida em Socorro (povoado pertencente a Barão de Cocais): o forro da capela-mor.

Os estudiosos de pinturas quadraturistas identificam duas tipologias nos tetos do século XVIII. O primeiro grupo é constituído por composições que se caracterizam pela utilização de tons penumbristas e cerrada trama arquitetônica ilusionista sustentando a cena central. O segundo conjunto reúne pinturas em tons mais claros e com a cena central sustentada por delgadas colunas e pilastras arrocalhadas ou simplesmente solta, envolta por nuvens, anjos e guirlandas de flores. As pinturas executadas por Gonçalo Francisco Xavier, localizadas nos templos anteriormente citados, apresentam aspectos estilísticos correspondentes às tipologias explicitadas.

A pesquisadora Myriam Ribeiro, na década de 1990, apontou a presença pioneira da rocalha no forro da nave de Santa Efigênia de Ouro Preto (OLIVEIRA,1997), de composição barroca da primeira fase e datado de 1768, situando esta obra no momento da introdução da temática rococó na pintura de perspectiva ilusionista mineira, seguida pela utilização do 
esquema compositivo de tarja central "solta" nos forros da nave de São Francisco de Assis (1782-1783) em Diamantina e da capela-mor da Matriz de Santana de Inhaí, ambos do Guarda-Mor José Soares de Araújo.

A partir de 1990 comecei a identificar, através da comparação de composições e elementos formais repetidos, seguindo o método morelliano, (Ginsburg, 1986) a "caligrafia" de um pintor em forros, retábulos e painéis parietais de algumas igrejas e capelas mineiras.

Todas as obras relacionadas compartilham tons de sua palheta e alguns elementos com a mesma forma e tratamento pictórico de volume idêntico: quartelões, romãs, volutas, enrolamentos terminados em forma de coruchéus e conchas nervuradas com bocetes, marcas sugerindo pontas de cravos para fixação, grisados paralelos para os planos e, para os volumes, sinuosas pinceladas sucessivas aos pares.

A composição das pinturas dos forros com "caligrafia" idêntica que relacionamos segue dois padrões: um com cerrada trama arquitetônica ilusionista envolvendo e sustentando a "visão" central, outro com tarja central "solta", circundada por guirlandas de flores. O segundo tipo de composição foi muito utilizado no rococó, o que poderia sugerir uma separação temporal significativa na fatura destas obras. Estas pinturas podem ser classificadas como decorativas; podem ser desenvolvimento das composições dos tetos decorados do brutesco nacional português com "visão" central (SERRÃO,1997), mas a generosa dimensão das molduras das tarjas centrais "soltas" e a decoração ao redor destas, com grinaldas, pássaros, tarjas menores e balaustradas as aproximam das composições de tarja central "solta" do rococó pleno. No entanto, o tom terroso dos fundos ao redor das tarjas centrais e a presença de bocetes nos elementos arquitetônicos ilusionísticos emprestam solidez a estas composições, mantendo-as ligadas ao barroco. Acrescentamos que nenhum dos forros com tarja central "solta" apresenta rocalha, indicando que a introdução do rococó se deu por uma inovação na composição das pinturas anterior ou paralela à assimilação da rocalha.

O forro da capela-mor de Santa Quitéria apresenta pintura com tarja central "solta", circundada por guirlandas de flores e pássaros sobre fundo marrom, com tarjas menores nos cantos. Todas as tarjas são constituídas por conchas, elementos fitomorfos e volutas.

O forro em abóbada de berço da capela-mor de Santana tem pintura com paleta em azul escuro, vermelho e ocres. A cerrada trama arquitetônica origina-se de bases acima das cimalhas. Duas pilastras de cada 
lado, encimadas por entablamentos, separam balcões. A abertura circular central é emoldurada por friso ornamentado com romãs vermelhas.

$\mathrm{Na}$ pintura do forro da sacristia a composição ilusionista sugere uma cúpula com abertura circular central por onde se observa um anjo pairando num céu com pequenas nuvens. O emolduramento da cena central é similar ao da capela-mor, sendo idêntico o friso com romãs vermelhas. Nos cantos da composição observamos tarjas formadas por enrolamentos em forma de corruchéus e volutas em tons de vermelho, azul e ocres. Entre as tarjas postam-se grandes aves marrons com asas estendidas para trás, bico adunco, olhos redondos e penacho sobre a cabeça.

Na composição espelhada dos dois painéis parietais da capela-mor observamos um arco abatido emoldurando pintura imitativa de azulejo. Nas laterais, quartelões de grande ressalto são adornados por conchas e unhas de gato. A superfície frontal do arco contem grisados em vermelho e branco, volutas marrons e romãs vermelhas.

O forro da capela-mor de Santa Quitéria apresenta pintura com tarja central "solta", circundada por guirlandas de flores e pássaros sobre fundo marrom. A "visão" central, a pomba do Espírito Santo sobre nuvens com querubins, é emoldurada por romãs em tons terrosos sobre fundo com pétalas de flores separadas por quadrículas (FIG. 1). Entre as tarjas dos cantos postam-se duas grandes aves em branco e cinza de cada lado, são similares às do forro da sacristia de Santana.

A pintura do forro da capela-mor do Rosário é de composição similar à de Santana. Os entablamentos dividem-se em duas sessões de cada lado, sustentados por arcos apoiados em dois pares de pilastras (FIG. 2). O medalhão com a "visão" central é quadrilobado, mas o friso de emolduramento é decorado por romãs vermelhas idênticas às de Santana.

$\mathrm{Na}$ igreja de Santo Antonio, matriz de Santa Bárbara, foram encontradas tábuas com resquícios de pintura de perspectiva, com partes de medalhão central e trama arquitetônica ilusionista circundante. Os elementos, as cores utilizadas e a forma do emolduramento da "visão" central são similares aos dos forros de Santana e Rosário. A pintura do entablamento do coroamento da portada da capela do Santíssimo Sacramento utiliza elementos similares aos utilizados nas tarjas de Santa Quitéria.

A pintura do forro da capela-mor da igreja de Socorro tem paleta em tons de vermelho, ocre, terras e azul claro. A composição é de tarja central "solta" circundada por guirlandas de flores e elementos fitomorfos 
vermelhos nos quatro cantos. Nesta pintura estão presentes elementos com as mesmas formas e com tratamento pictórico idêntico aos utilizados em Santa Quitéria. A tarja é constituída pelos mesmos tipos de enrolamentos em forma de coruchéus, elementos fitomorfos e conchas.

Sabemos da contratação de Gonçalo Francisco Xavier pela Irmandade do Santíssimo Sacramento para a pintura e douramento da sua capela e da "porta da caza da fábrica" na Matriz de Santo Antônio, em Santa Bárbara, a 20 de janeiro de 1756 (AEAM. Livro 12, fls. 39v). Tendo sido esta igreja reconstruída em anos posteriores, os elementos artísticos da Matriz de Santa Bárbara que relacionamos anteriormente provavelmente pertenceram à sua primitiva decoração: sendo as tábuas de forro, lá recentemente encontradas, remanescentes do forro da Capela da Irmandade do Santíssimo Sacramento e a portada desta capela a "porta da caza da fábrica", citada em documento. Deste pintor, sem obra identificada até o momento, sabemos também que prestou exame de ofício em 1742 na antiga Vila Rica (APM. Fls 110, Livro no 41). Foi processado por não pagamento de material de pintura pelo comerciante João Gonçalves Bragança e condenado em 1772, sendo declarado pobre (ACS. Códice 482 a 10764).

Por comparação estilística agrupamos as obras apresentadas, atribuindo-as a este autor. Trabalhamos também com a hipótese de que a mudança do gosto estético representado pelo rococó foi, anteriormente à importação do modelo europeu da rocalha, introduzido desde o momento em que as pinturas com tarja central "solta" começaram a figurar nos tetos dos templos mineiros.

É necessário analisar a iconografia e a simbologia contida nas pinturas, tentar compreender as histórias que guardam.

"Falar do monumento barroco também pressupõe a possibilidade de analisá-lo segundo três grandes recortes... o primeiro é o dos esquemas retórico-poéticos que, na forma de lugares-comuns e ornatos, estruturam sua espacialidade ou visualização alegórica; o segundo é o dos assuntos contemporâneos dramatizados nos esquemas; o terceiro, o da interpretação teológico-política dos assuntos e dos esquemas, evidenciada como um apelo ao destinatário da obra nos discursos esculpidos, signos plásticos e, ainda, na relação sintática que se estabelece entre as imagens e os discursos aplicados. É oportuno insistir no valor posicional ou sintático dos signos, pois a ordem que recebem também define sua significação.”(HANSEN, 1997, p. 44)

O estudo da passagem da pintura decorativa mineira do ciclo barroco ao rococó não está esgotado e o aporte de dados novos sobre esta questão pode contribuir para ampliar a compreensão da arte do período. 
O avanço das pesquisas na área de história cultural tem levado cada vez mais a uma parceria privilegiada com a história social. Recompor os valores e mentalidades de uma época através da ação de seus artistas e de sua inserção no universo cultural das Minas setecentistas, indistintas e hierarquizadas é uma das maneiras mais eficientes de resgatar relações culturais que por sua circularidade deixou pistas difusas e por vezes contraditórias. Evitar os disparates de uma análise superficial calcada apenas no discurso da documentação escrita é ignorar o quanto a iconografia, apesar de suas limitações, incorporava aspectos da religiosidade popular e do dogmatismo tridentino. Estudar um pintor como Gonçalo pode ser o caminho para recompor um quadro muito mais amplo, como já nos ensinou Ginsburg em seu "O Queijo e os Vermes".

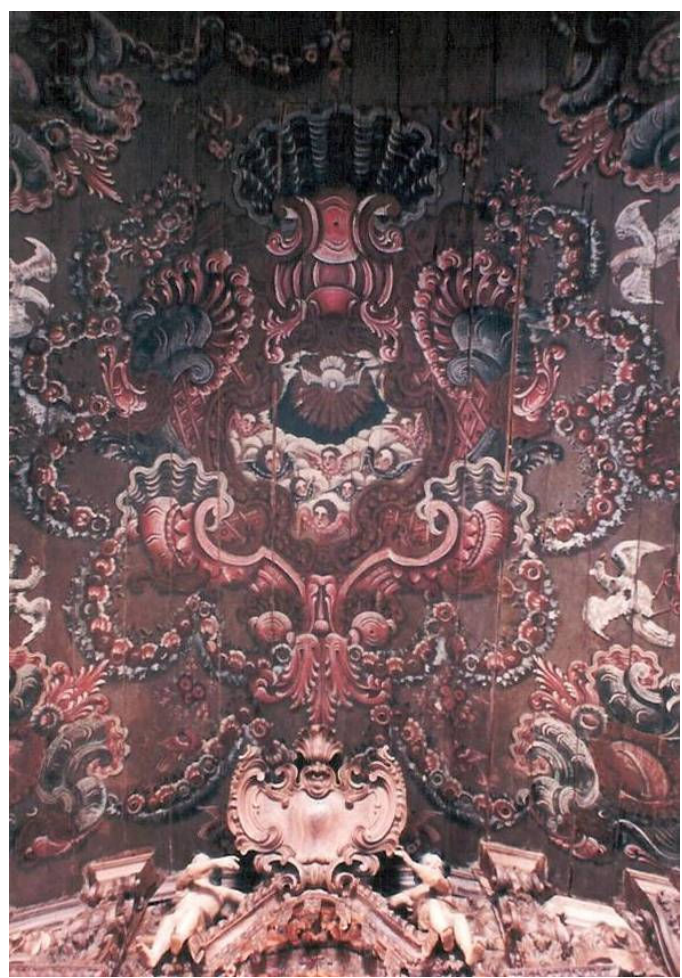

FIG. 1 - Forro da capela-mor da igreja de Santa Quitéria

Gonçalo Francisco Xavier, Catas Altas (MG). Tarja central "solta". Foto do arquivo do IEPHA/MG 


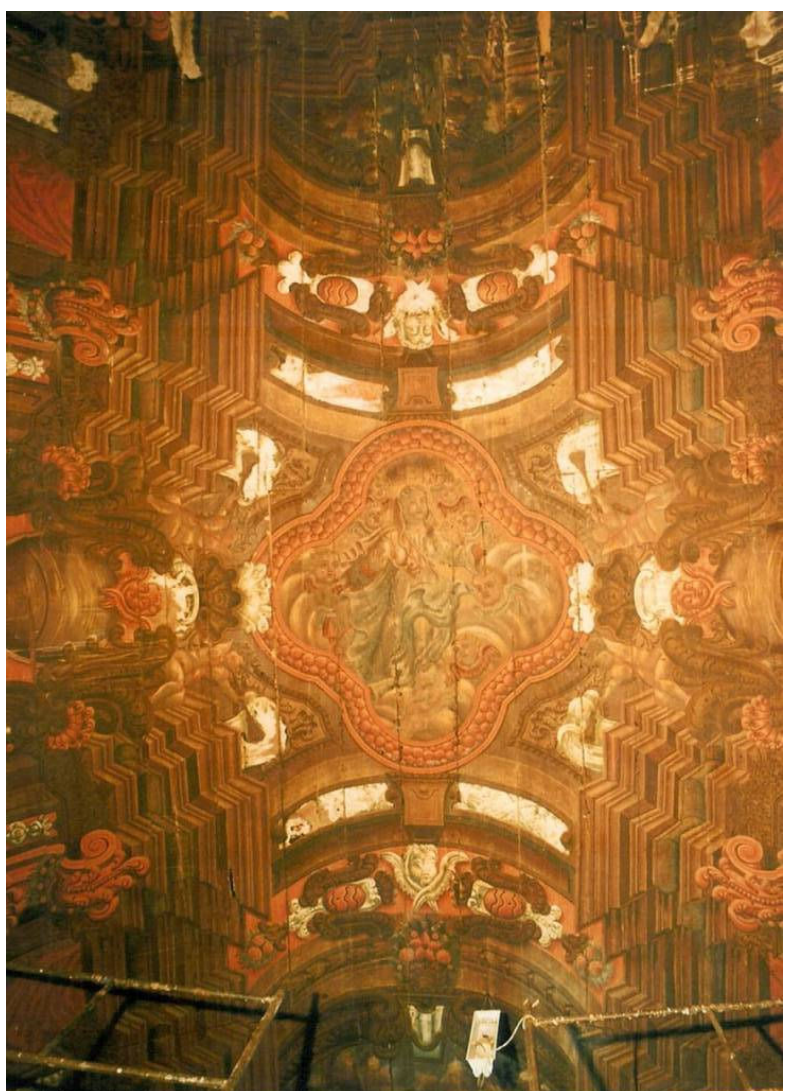

FIG. 2 - Forro da capela-mor da igreja de Nossa Senhora do Rosário Gonçalo Francisco Xavier, Catas Altas (MG). Trama arquitetônica cerrada. Foto do arquivo do IEPHA/MG

\section{Bibliografia}

ÀVILA, Affonso. Resíduos seiscentistas em Minas. Belo Horizonte: UFMG, 1967.

ÁVILA, Affonso. O lúdico e as projeções do mundo Barroco. São Paulo: Perspectiva, 1992.

Ávila, Affonso. et al. Barroco Mineiro: Glossário de arquitetura e ornamentação. Belo Horizonte: Fundação João Pinheiro, 1996.

ÁVILA, Affonso (Org.). Barroco: teoria e análise. São Paulo: Perspectiva; Belo Horizonte: Companhia Brasileira de Metalurgia e Mineração, 1997.

ÀVILA, Affonso (Org.). Barroco. no 19. 2005.

BAZIN, Germain. Barroco e Rococó. São Paulo: Martins Fontes, 1993.

BAZIN, Germain. Arquitetura religiosa barroca no Brasil. Rio de Janeiro: Record, 1983. 
CAMPOS, Adalgisa Arantes (Org.). Manoel da Costa Athaide: Aspectos históricos, estilísticos, iconográficos e técnicos. Belo Horizonte: C/Arte, 2005.

CAMPOS, Adalgisa Arantes. Introdução ao Barroco mineiro. Belo Horizonte: Crisálida, 2006.

GINSBURG, Carlo. Mitos emblemas sinais. São Paulo: Companhia da Letras, 1986.

GINSBURG, Carlo. Nenhuma ilha é uma ilha. São Paulo: Cia das Letras, 2002. p.83.

HANSEN, João Adolfo. Notas sobre o “Barroco”. Revista do IFAC, no 2 , p 44 , dez 1995.

OLIVEIRA, Myriam Andrade Ribeiro. O Rococó religioso no Brasil e seus antecedentes europeus. São Paulo: Cosac \& Naify, 2003.

SILVEIRA, Marco Antônio. O universo do indistinto: Estado e Sociedade nas Minas setecentistas (17351808). São Paulo: Editora Hucitec. 1997.

SOUZA, Laura de Mello. Inferno no Atlântico: demonologia e colonização séculos XVI - XVIII. São Paulo: Cia das Letras, 1993.

MARAVALL, José Antonio. A Cultura do Barroco: uma análise de uma estrutura histórica. São Paulo: Edusp, 1997. 